other change in treatment or general condition of the patient, such as acute infection, the stoppage of guanethidine appears to have been responsible for this increase in blood sugar levels and increased insulin requirements. There is no published report on the effect of guanethidine on severity of diabetes. However, Woeber et al. reported reversal by guanethidine of abnormal glucose tolerance in patients with thyrotoxicosis. ${ }^{1}$ In rats, guanethidine $20 \mathrm{mg} . / \mathrm{kg}$. intraperitoneally daily for four days produced a slight fall in blood sugar. Chronic pretreatment with guanethidine in a dose of $20 \mathrm{mg} . / \mathrm{kg}$. daily has been found to modify the hyperglycaemic response to ether anaesthesia. The maximum increase in blood sugar was diminished, but the overall rise appeared to be somewhat prolonged. ${ }^{2} 3$ In rabbits, on the other hand, Parikh et al. ${ }^{4}$ showed a hyperglycaemic action of guanethidine and also that it potentiated the hyperglycaemic action of epinephrine in a smaller dose, which itself had no effect on blood sugar. Intravenous administration of guanethidine $0.4 \mathrm{mg} . / \mathrm{kg}$. in seven patients with hypertension was found to cause slight hyperglycaemia after three hours. ${ }^{5}$ Guanethidine causes release of epinephrine, and epinephrine has been experimentally shown to inhibit pancreatic insulin release. ${ }^{6}$ However, the results of chronic administration of guanethidine, when tissues are depleted of epinephrine, may well be different from this acute effect. Guanethidine significantly reduced the hyperglycaemic response to diazoxide in adrenal demedullated rats.

This last finding may have some relevance to the present case, since she had been on bendrofluazide $5 \mathrm{mg}$. daily for the last six months. It is possible that guanethidine was blocking the hyperglycaemic action of bendrofluazide, which became manifest dramatically when the former was discontinued. This case is being reported as an interesting clinical observation. The explanation of this phenomenon would need further clinical and experimental pharmacological investigations. We would be most interested in knowing if such a tendency has been noted in other patients in similar clinical situations.-We are, etc.,

County Hospital,
Lincoln.

\section{K. K. Gupta.}

Lincoln.

C. A. Lillicrap

REFERENCES

Woeber, K. A., Arky, R., and Braverman, L. E., Manninen, K., Mäenpäa, M., and Pekkarinen A., Acta physiol. scand., 1963, 59, Suppl. No. 213, 97 .

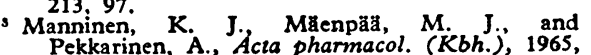
22, 310 .

Parikh, H. M., Gulati, O. D., and Gokhale, S. D., Ind. '7. Physiol. Pharmacol., 1963, 7, Okun, R., Wilson, W. R., and Gelfand, M. D., 7.

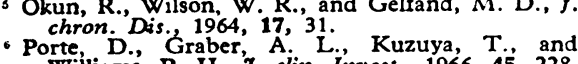

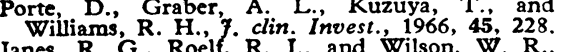

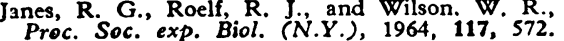

\section{Deaths from Asthma}

SIR,-I have followed the correspondence on deaths from asthma with interest, and I am grateful to Drs. I. W. B. Grant and others (18 May, p. 429) for their comments on four cases of cardiac arrest due to status asthmaticus occurring in hospital. However, their statement that "when a patient with status asthmaticus develops cardiac arrest in hospital and this is shown to be due to ventricular asystole the proper course is to undertake open cardiac massage without delay" appears to be rather dogmatic. My experience of one case is reported below, in which the conventional conservative measures for the treatment of asystole were effectivenamely, intracardiac adrenaline $(1: 10,000)$ with or without calcium chloride $10 \%$ intravenously.

A female asthmatic aged 44 years was readmitted with status asthmaticus on 13 February 1967. She was obese, her pulse rate $120 / \mathrm{min}$. She was treated with intravenous A.C.T.H., oral prednisone, and ampicillin, and during the next 24 hours her condition improved. In the early hours of 15 February she awoke with sudden dyspnoea and collapsed within minutes. External cardiac massage and artificial ventilation were started promptly by the nursing staff, and intravenous sodium bicarbonate was given. Chest compression produced palpable femoral pulses, while the E.C.G. showed asystole. Five millilitres of adrenaline $1: 10,000$ was injected into the heart, and external massage continued for a further minute. Cardiac rhythm was restored, the E.C.G. showing a supraventricular tachycardia, rate $170 / \mathrm{min}$. She was intubated, and ventilated with an East Radcliffe respirator. An intravenous infusion of hydrocortisone was also given, and she made an uninterrupted recovery from this episode. She was discharged home on 1 March.

The experience of this single case agrees with the view of Dr. Grant and his colleagues that ventricular asystole occurs in status asthmaticus. In this instance conservative measures were successful in restoring an effective cardiac rhythm. This case shows that intracardiac adrenaline, with or without intravenous calcium chloride, has a place in the treatment of asystole due to status asthmaticus, and should be considered before resorting to open cardiac massage.

I wish to thank Dr. Byron Evans for his permission to publish the details of this case, and Dr. D. A. Williams for his helpful advice. -I am, etc.,

$$
\begin{aligned}
& \text { Llandough Hospital, GLYNNE R. JONEs. } \\
& \text { Penarth, } \\
& \text { Glam. }
\end{aligned}
$$

\section{Pregnancy and Monoamine Oxidase Inhibitors}

SIR,-Neither your article (6 April, p. 35) nor your correspondents Mr. A. G. Johnson and Dr. M. F. Cuthbert (18 May, p. 433) mentioned the hazard of monoamine oxidase inhibitors (M.A.O.I.) during pregnancy. The literature makes it perfectly clear that it is not safe to give a patient who is on a monoamine oxidase inhibitor a local anaesthetic, a general anaesthetic, amphetamines, barbiturates, tricyclic antidepressants, or pethidine, not to speak of another M.A.O.I. ${ }^{2}$ This is a formidable risk when one considers that any pregnancy may abort and the mother need at least sedation or even evacuation of the uterus. In later pregnancy there are all sorts of eventualities to consider, quite apart from the fact that the onset of labour is something which cannot be predicted or anticipated.

According to the excellent survey of the literature given in chapters 11 and 12 of Psychopharmacological Agents, ${ }^{2}$ it takes a month for the effects of an M.A.O.I. to wear off completely. Unfortunately neither a threatened abortion nor a premature labour will wait two weeks before treatment can be begun. Hence it would seem wise to wean women from M.A.O.I.s at the beginning of pregnancy, and it has been my practice to do this. Unfortunately the weaning process is difficult, and my last three patients have experienced a number of discomforts from the second to the tenth day after withdrawal. These discomforts included headache, agitation, sweating, and changes in the pattern of sleep. The agitation produced what sounded like acute anxiety attacks, and two of the patients felt driven to ask another doctor for supplies of their drug, but refrained from doing so because they knew their state was temporary. The most difficult symptom to deal with was their depression. Nobody who has seen the headache which develops when a patient on an M.A.O.I. is given imipramine wishes to repeat the experiences.

I understand that M.A.O.I.s are being used to induce abortion. The sort of women who are likely to wish for a termination of pregnancy will include patients already taking M.A.O.I.s The risk of a fatality from cerebral haemorrhage when such a technique is used must be carefully considered, and the patient will have to face either a period of acute stress while her drug is being withdrawn or the slightly smaller but still considerable risks of other methods of terminating pregnancy.-I am, etc.,

University College Hospital,

Elizabeth Tylden.

\section{REPBRENCES}

The Scientific Basis of Drug Therapy in Psychiatry, edited by J. Marks and C. M. B. Pare, Psychopharmacological Agents, edited by M.
Gordon, 1964, vol. I. New York.

\section{Oral Contraceptives in the Post-partum Period}

SIR,-We wish to draw attention to some of the limitations of the paper by Dr. A. Nilsson and Mr. P.-E. Almgren on psychiatric symptoms during the post-partum period as related to the use of oral contraceptives (25 May, p. 453). The authors conclude a causal relation between oral contraceptives and psychiatric symptoms, and that these symptoms should be ascribed to hormonal factors. Our first point concerns the observation that the group of women who take oral contraceptives in the post-partum period must show some psychological differences from the group of women who use other methods of contraception, because the first group were "more anxious to use a safe method." It might therefore be hypothesized that those women who were more anxious for reliable contraception are less able to cope with a new baby in the family, and therefore at greater risk from post-partum psychiatric symptoms-hormonal factors are not a necessary condition of the findings of this paper, and the relation is not necessarily causal. Our second point is that the choice between oral contraception and other methods is made in the post-partum period, and that is just the period during which the differences in incidence of psychiatric symptoms have been demonstrated in this paper. The possibility that oral contraception is chosen because of the high incidence of post-partum psychiatric 